\title{
ИССЛЕДОВАНИЕ ВОЗМОЖНОСТИ ФУНКЦИОНАЛИЗАЦИИ НАНОПЛАСТИНОК ОКСИДА ГРАФЕНА ФОТОХРОМНЫМИ ХРОМЕНОМ И СПИРОПИРАНАМИ В РАСТВОРАХ
}

\author{
О. В. Венидиктова, А. М. Горелик, В.А. Барачевский, А. А. Хузин, А. Р. Туктаров \\ ОЛЬГА ВЛАДИМИРОВНА ВЕНИДИКТОВА - научный сотрудник лаборатории фотохромных систем \\ Центра фотохимии ФНИЦ «Кристаллография и фотоника» PAH. E-mail: wolga.photonics@inbox.ru.

\begin{abstract}
АЛЕКСАНДР МИХАЙЛОВИЧ ГОРЕЛИК - к.х.н., стариий научный сотрудник лаборатории фотохромных систем Центра фотохимии ФНИЦ «Кристаллография и фотоника» PAH. E-mail: 77gorelik@mail.ru.
\end{abstract} \\ ВАЛЕРИЙ АЛЕКСАНДРОВИЧ БАРАЧЕВСКИЙ - к.ф.-м.н., с.н.с., ведущчий научный сотрудник, заведующий \\ лабораторией фотохромных систем Центра фотохимии ФНИЦ «Кристаллография и фотоника» РАН, \\ ФГБУН Межведомственный центр аналитических исследований в области физики, химии и биологии при \\ Президиуме РAH. E-mail: barachevsky@mail.ru
}

АРТУР АЛЬБЕРТОВИЧ ХУЗИН - к.х.н., научный сотрудник Института нефтехимии и катализа УФИЦ PAH.E-mail: artur.khuzin@gmail.com.

АЙРАТ РАМИЛЕВИЧ ТУКТАРОВ - д.х.н., профессор РАН, ведущฺий научный сотрудник Института нефтехимии и катализа УФИЦ РАН. E-mail: tuktarovar@gmail.com.

119421, г. Москва, ул. Новаторов, 7а, к.1, Центр фотохимии ФНИЦ «Кристаллография и фотоника» РАН.

117997, Россия, г. Москва, ул. Профсоюзная, д. 65, стр. 6, ФГБУН Межведомственньй центр аналитических исследований в области физики, химии и биологии при Президиуме РАН.

450075, Россия, Республика Башкортостан, г. Уфа, пр. Октября, 141. Институт нефтехимии и катализа УФИЦ РАН.

Представлень результаты спектрально-кинетического исследования взаимодействия поверхностных групп нанопластинок оксида графена с молекулами фотохромных соединений из классов хроменов и спиропиранов в растворах. Показано, что при взаимодействии поверхностных гидроксильных групп оксида графена с молекулами спиропиранов возникают протонные комплексы, проявляющие отрицательный фотохромизм. В случае хромена обнаружены спектрально менее выраженные взаимодействия, обусловленные, предположительно, физической адсорбичей молекул на поверхности нанопластинок оксида графена.

Ключевые слова: спектроскопия, оксид графена, спиропиран, хромен, протонный комплекс. 


\title{
STUDY OF THE POSSIBILITY \\ OF FUNCTIONALIZATION OF GRAPHENE OXIDE NANOPLATES WITH PHOTOCHROMIC CHROMENE AND SPIROPYRANS IN SOLUTIONS
}

\author{
O.V. Venidiktova ${ }^{1}$, A. M. Gorelik ${ }^{1}$, V.A. Barachevsky ${ }^{1,2}$, A.A. Khuzin ${ }^{3}$, A. R. Tuktarov ${ }^{3}$ \\ ${ }^{1} 7$ A Novatorov st., b. 1, Moscow, 119421, Russia. Photochemistry Center of FSRC "Crystallography and Photonics" \\ of the Russian Academy of Sciences. \\ ${ }^{2} 65$ Profsoyuznaya Street, Moscow, 117997, Russia. Interdepartment Center of Analytical Research in the field \\ of Physics, Chemistry, and Biology, Presidium of the Russian Academy of Sciences. \\ ${ }^{3} 141$ pr. Oktyabrya, Ufa, Bashkortostan, 450075, Russia. Institute of Petrochemistry and Catalysis petrochemistry \\ and catalysis of the Russian academy of sciences.
}

The results of spectral-kinetic studies of the interaction of surface groups of graphene oxide nanoplates with molecules of photochromic compounds from the classes of chromenes and spiropyrans in solutions are presented. It is shown that the interaction of surface hydroxyl groups of graphene oxide with spiropyran molecules gives rise to proton complexes exhibiting negative photochromism. In the case of chromene, spectrally less pronounced interactions were detected, presumably due to physical adsorption of molecules on the surface of graphene oxide nanoplates.

Keywords: spectroscopy, graphene oxide, spiropyrane, chromene, proton complex.

\section{Введение}

Ранее в результате сравнительного спектрального исследования жидкостных и твердофазных систем, содержащих нанопластинки оксида графена и фотохромные соединения из классов диарилэтенов и спирооксазинов, обнаружены спектральные проявления взаимодействия между этими компонентами систем [1]. Анализ полученных результатов позволил сделать вывод о возможности функционализации поверхности наночастиц графена тиол-замещенными фотохромными молекулами, особенно из класса спирооксазинов.

В данной статье в развитие этих исследований проведено спектрально-кинетическое исследование взаимодействия ряда новых функционализированных фотохромных соединений из классов хроменов и спиропиранов с поверхностью нанопластинок оксида графена. Механизм фотохромных превращений этих классов соединений представлен на схемах 1 и 2 [2].<smiles>[R]c1ccc(C2(c3ccc([R])cc3)C=Cc3c(ccc4ccccc34)O2)cc1</smiles>

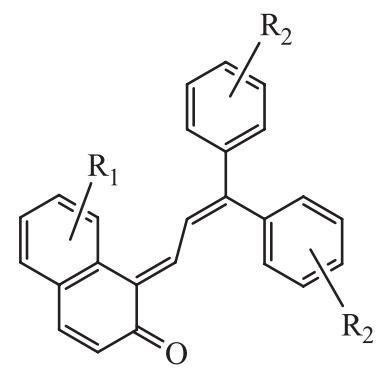

Схема 1. Фотохромные превращения хроменов 


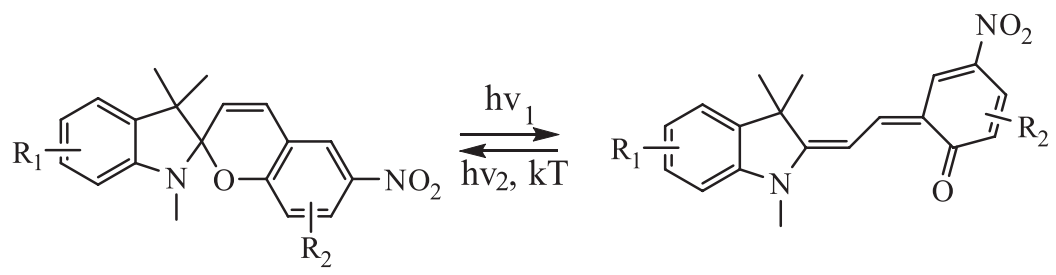

Схема 2. Фотохромные превращения спиропиранов

\section{Экспериментальная часть}

В качестве объектов исследования использовались функционализированные хромен, а также нитрозамещенные спиропираны (схема 3).

Бис-хромен 1 синтезирован с использованием методики [3] в результате взаимодействия 3,3'-дифенил-8-гидрокси-3Н-нафто[2,1-b]пирана с 3,3'-дитиодипропионовой кислотой в присутствии дициклокарбодиимида и пирролидонпипиридина (DCC метод). Выход конечного продукта составлял $10 \%$.

Синтез спиропирана 2 со свободной меркаптогруппой включал получение нитроспиропиранакриловой кислоты и последующее взаимодействие с тионилхлоридом и 1,2-аминотиолом.

Спиропиран 3 был получен по хорошо описанной методике [4]. Синтез и свойства соединения 4 описаны ранее [5].

Нанопластинки оксида графена, синтезированного по модифицированному методу Хаммерса [6], были получены из ИПХФ РАН.

Для исследования смешивали в равных объемных соотношениях растворы соединений с концентрацией $\mathrm{C}=2 \cdot 10^{-4} \mathrm{M}$ в ацетонитриле $(99,8 \%$, без-<smiles>O=C(CCSCCC(=O)Oc1ccc2c3c(ccc2c1)OC(c1ccccc1)(c1ccccc1)C=C3)OC1=CC=C2c3ccc(cc32)OC1(c1ccccc1)c1ccccc1</smiles>

1

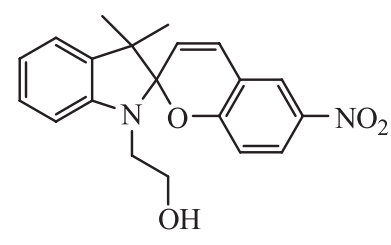

3 водный, фирмы «Sigma-Aldrich») и разбавленный в два раза бидистиллированной водой концентрированный раствор оксида графена $(0,08$ мг/мл на 1 ед. Д (400 нм)). Смеси выдерживали при комнатной температуре в темноте 1-3 суток перед исследованием.

Спектрально-кинетические исследования растворов проводились на спектрофотометре Cary-60 UV-Vis («Agilent Technologies»).

Базовую линию регистрировали с использованием смеси ацетонитрил-вода (1:1 по объему) в рабочей кювете из кварца марки КУ-1 с оптическим путем 2 мм. Спектры поглощения смеси фотохромное соединение - вода/оксид графена были зарегистрированы в той же кварцевой кювете. После регистрации исходного спектра поглощения раствор смеси облучали УФ светом, регистрируя при этом спектры поглощения в циклическом режиме. Затем перекрывали свет, регистрировали спектры темновой релаксации, а при отсутствии таковой, регистрировали спектры после облучения смеси видимым светом в циклическом режиме. Циклический режим является приборной настройкой. Задержка между циклами составляла 0 мин. Среднее время сканирования с задержкой - около 9 с.<smiles>CN1c2ccc(/C=C/C(=O)NCCS)cc2C(C)(C)C12CC=Cc1cc([N+](=O)[O-])ccc1O2</smiles>

2

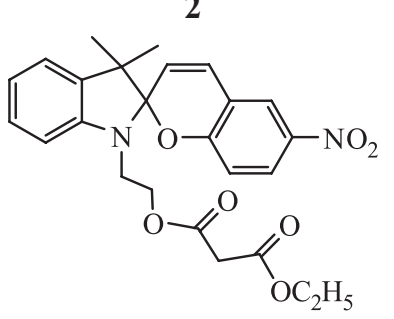

4

Схема 3. Структуры исследованных фотохромных соединений 


\section{Результаты исследования и их обсуждение}

На рис. 1 приведены фотоиндуцированные и спонтанные изменения спектров поглощения раствора бис-дисульфида 1 в толуоле, а на рисунках 2 и 3 - изменения разностных спектров поглощения вещества в водно-ацетонитрильном раствоpe.

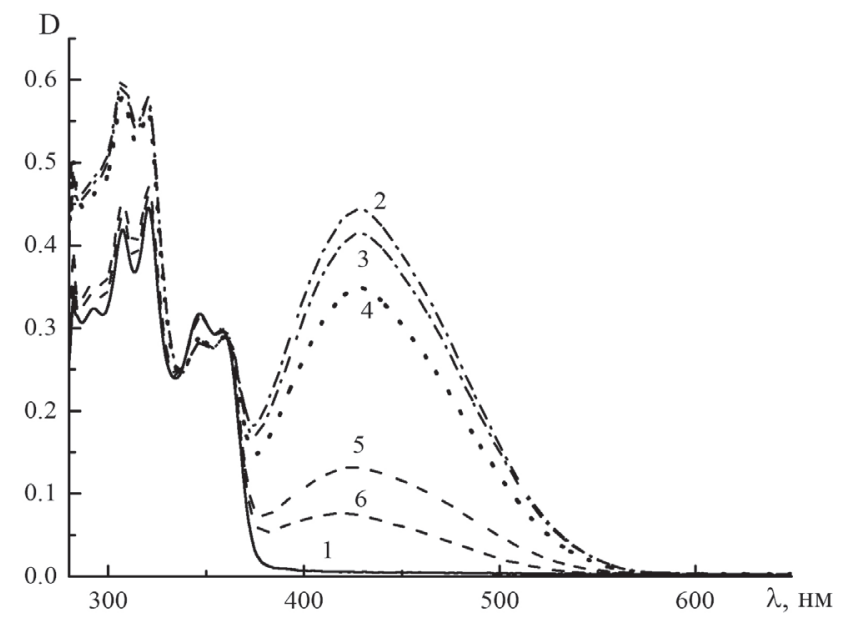

Рис. 1. Спектры поглощения раствора соединения 1 в толуоле $\left(C=2 \cdot 10^{-4} \mathrm{M}\right)$ до (1), после УФ облучения (2) и последующей спонтанной релаксации фотоиндуцированной мероцианиновой формы (3-6)

В спектре поглощения соединения 1 в толуоле появляется фотоиндуцированная полоса поглощения с максимумом при 430 нм (рис. 1, кр. 2), интенсивность которой спонтанно снижается с константой скорости $\mathrm{k}_{\text {то }}=0,243 \mathrm{c}^{-1}$ после отключения активирующего излучения. Этот процесс повторяется неоднократно. Таким образом, бисхромен 1 проявляет фотохромные превращения, типичные для хроменов, и характеризуется, как и все хромены, высокой устойчивостью к необратимым фотопревращениям.

Это соединение проявляет менее эффективные фотохромные превращения в водно-ацетонитрильном растворе (рис. 2).

Для анализа спектров поглощения молекул фотохромных соединений в присутствии нанопластинок оксида графена использовались разностные спектры с целью исключения влияния на них светорассеяния, обусловленного нанопластинками, а также влияния нераскрывшихся молекул спироформы. Они получены путем вычитания спектра поглощения раствора спироформы соединений с нанопластинками из спектров поглощения растворов, содержащих мероцианиновую форму соединения и нанопластинки.

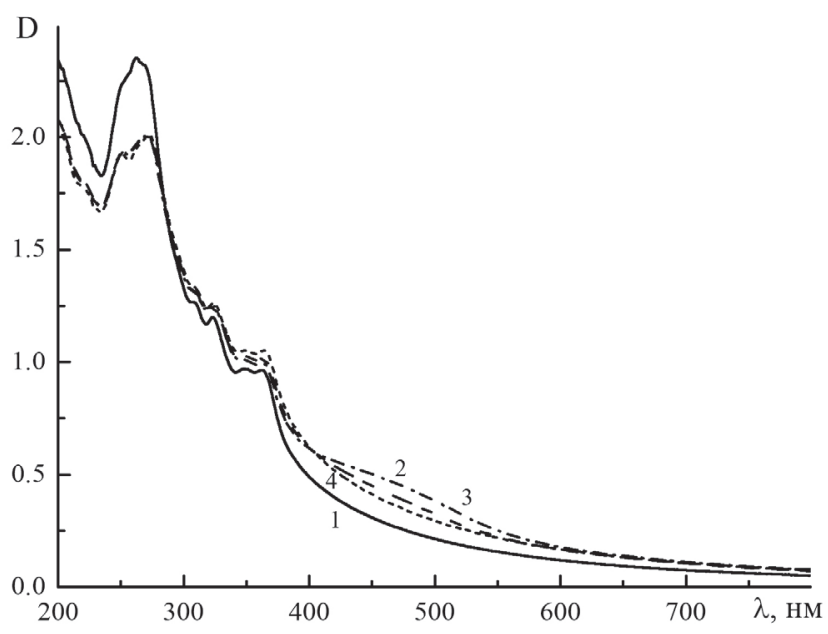

Рис. 2. Спектры поглощения соединения 1 в водно-ацетонитильной смеси до (1), после УФ облучения (2), в процессе темновой релаксации (3) и последующего облучения видимым светом (4)

При УФ облучении соединения 1 в водно-ацетонитрильной смеси также происходит его превращение в открытую окрашенную форму с появлением полосы поглощения в области 420-600 нм с максимумом при 465 нм (рис. 3, кр. 2; табл. 1). Эта полоса исчезает в процессе темновой релаксации (рис. 3, кр. 3) и при дополнительном облучении видимым светом (рис. 3 , кр. 4).

Как видно из рис. 3, процессы темновой релаксации и обесцвечивания видимым светом происходят достаточно быстро. При этом наблюдается изобестическая точка при 403 нм.

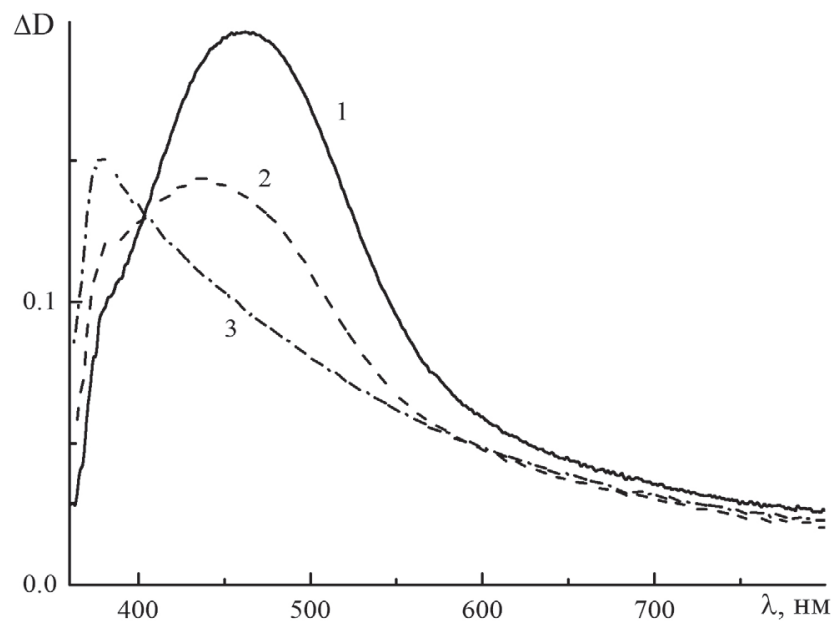

Рис. 3. Разностные спектры поглощения соединения 1 в водно-ацетонитильной смеси после УФ облучения (1), в процессе темновой релаксации (2) и после облучения видимым светом (3) 
О.В. Венидиктова и др.

Спектральные характеристики исследованных соединений

\begin{tabular}{|c|c|c|c|c|}
\hline Соединение & $\begin{array}{c}\text { Наличие оксида } \\
\text { графена }\end{array}$ & $\lambda_{\mathrm{A}}^{\text {макс }}, \mathbf{H M}$ & $\lambda_{\mathrm{B}}^{\text {макс }}, \mathbf{H M}$ & $\Delta \lambda$ \\
\hline \multirow{7}{*}{1} & \multirow{4}{*}{-} & 262 & \multirow{4}{*}{462} & \multirow{4}{*}{0} \\
\hline & & 324 & & \\
\hline & & 348 & & \\
\hline & & 362 & & \\
\hline & \multirow{3}{*}{+} & 271 & \multirow{3}{*}{470} & \multirow{3}{*}{+8} \\
\hline & & 326 & & \\
\hline & & 363 & & \\
\hline \multirow{5}{*}{2} & \multirow{3}{*}{-} & 224 & \multirow{3}{*}{542} & \multirow{3}{*}{0} \\
\hline & & 266 & & \\
\hline & & 348 & & \\
\hline & \multirow{2}{*}{+} & 229 & \multirow{2}{*}{432} & \multirow{2}{*}{-110} \\
\hline & & 345 & & \\
\hline \multirow{5}{*}{3} & \multirow{3}{*}{-} & 244 & \multirow{3}{*}{521} & \multirow{3}{*}{0} \\
\hline & & 270 & & \\
\hline & & 346 & & \\
\hline & \multirow[t]{2}{*}{+} & 264 & \multirow[t]{2}{*}{409} & \multirow[t]{2}{*}{-112} \\
\hline & & 342 & & \\
\hline \multirow{5}{*}{4} & \multirow{3}{*}{-} & 243 & \multirow{3}{*}{535} & \multirow{3}{*}{0} \\
\hline & & 270 & & \\
\hline & & 343 & & \\
\hline & \multirow{2}{*}{+} & 263 & \multirow{2}{*}{412} & \multirow{2}{*}{-123} \\
\hline & & 340 & & \\
\hline
\end{tabular}

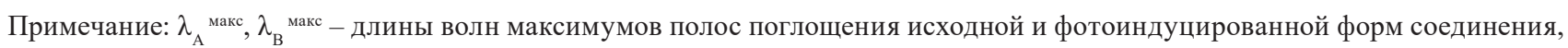
соответственно; $\Delta \lambda$ - сдвиг максимума полосы фотоиндуцированной формы («-»- гипсохромный сдвиг, «+»- батохромный сдвиг) по отношению к максимуму этой же полосы без окисида графена в растворе.

При введении в фотохромную водно-ацетонитрильную смесь частиц оксида графена происходит изменение спектральных характеристик. Максимум полосы фотоиндуцированной формы смещается батохромно на 8 нм. Из кривых, приведенных на рис. 4, видно, что интенсивность полосы поглощения фотоиндуцированной формы (рис. 4, кр. 1) в процессе темновой релаксации (рис. 4, кр. 2) и последующего облучения видимым светом (рис. 4, кр. 3) снижается с появлением полосы поглощения в области $375-420$ нм. В отличие от раствора соединения 1 , не содержащего оксида графена, изобестическая точка отсутствует.

Спиропиран с тиольным заместителем 2 в водно-ацетонитрильной смеси приобретает окраску до облучения и характеризуется спектром фотоиндуцированного поглощения с максимумом при 542 нм (табл. 1). Он проявляет обратный фотохромизм (рис. 5). При УФ облучении раствора интенсивность полосы поглощения возрастает, а максимум полосы поглощения смещается

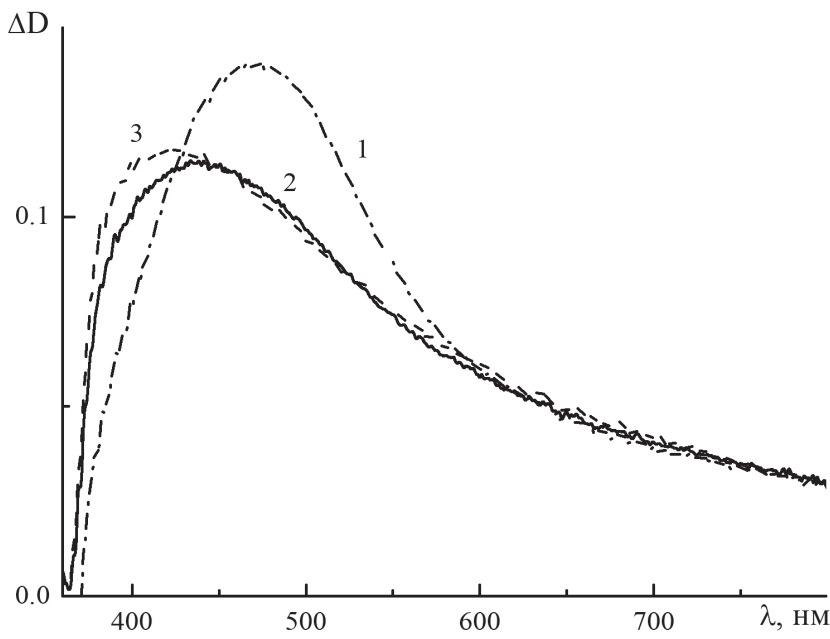

Рис. 4. Разностные спектры поглощения соединения 1 в водно-ацетонитильной смеси в присутствии оксида графена после УФ облучения (1), в процессе темновой релаксации (2) и после облучения видимым светом (3) 
на 36 нм в коротковолновую область (рис. 6, кр. 1). Спектр поглощения незначительно меняется в темноте (рис. 6, кр. 2). Видимое излучение приводит к обесцвечиванию раствора (рис. 6, кр. 3).

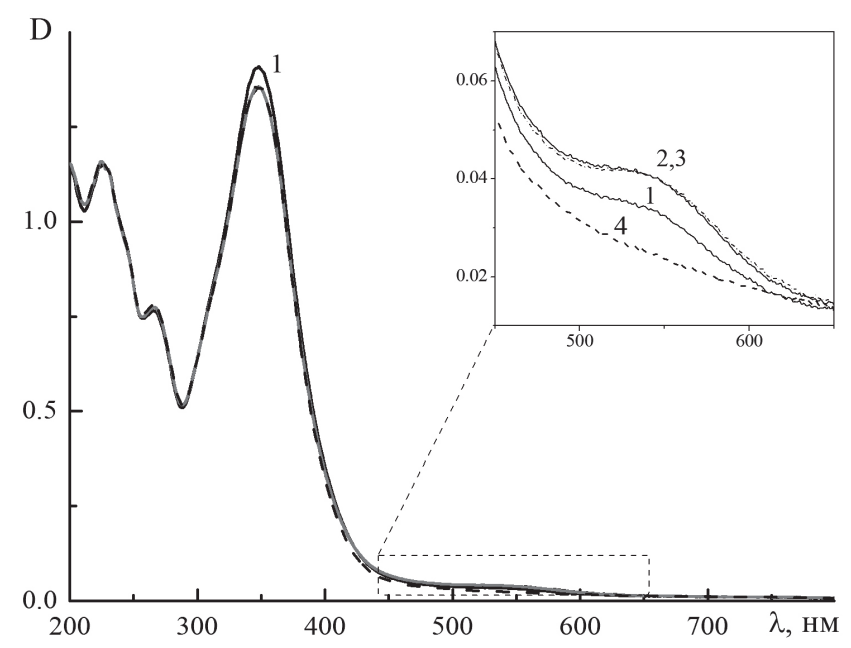

Рис. 5. Спектры поглощения соединения 2 в водно-ацетонитильной смеси до (1), после УФ облучения (2), в процессе темновой релаксации (3) и последующего облучения видимым светом (4)

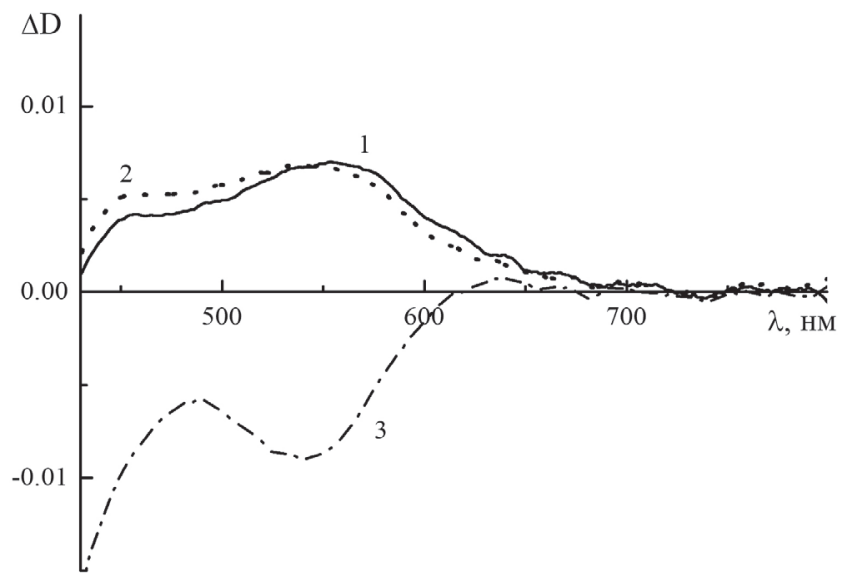

Рис. 6. Разностные спектры поглощения соединения 2 в водно-ацетонитильной смеси после УФ облучения (1), темновой релаксации (2) и облучения видимым светом (3)

При добавлении оксида графена максимум полосы фотоиндуцированной формы соединения 2 сдвигается гипсохромно еще на 110 нм по сравнению аналогичным спектром поглощения водноацетонитрильной смеси (рис. 7, кр. 1; табл. 1). Как и для раствора без оксида графена, темновая реакция малоэффективна (рис. 7, кр. 2). Обесцвечи- вание раствора наблюдается при облучении видимым светом (рис. 7, кр. 3). Резкое гипсохромное смещение полосы поглощения мероцианиновой формы спиропирана может быть объяснено образованием протонированных комплексов молекул спиропирана 2 в результате образования водородных связей с поверхностными гидроксильными группами оксида графена.

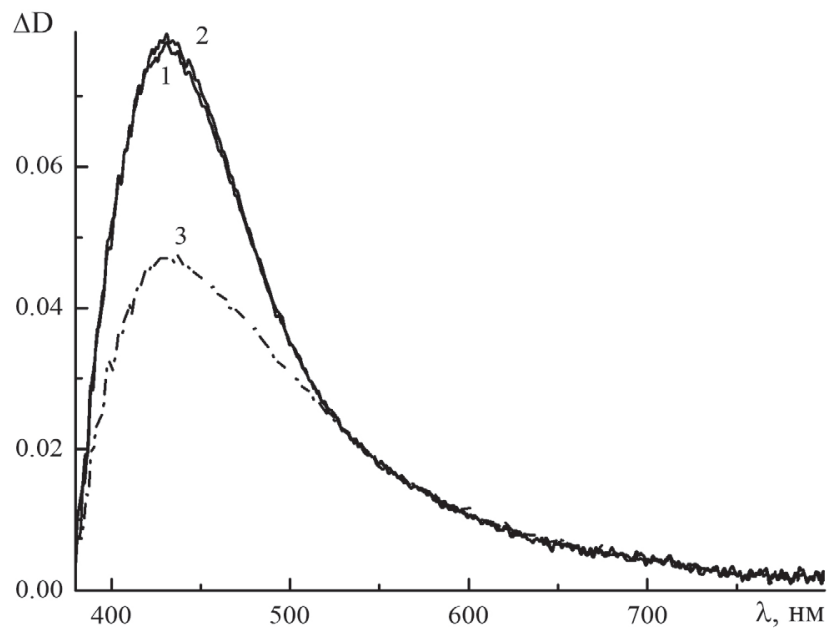

Рис. 7. Разностные спектры поглощения соединения 2 в водно-ацетонитильной смеси в присутствии оксида графена

после УФ облучения (1), темновой релаксации (2) и облучения видимым светом (3)

Обратный фотохромизм проявляет и гидрокси-содержащий нитрозамещенный индолиновый спиропиран 3 (рис. 8, 9).

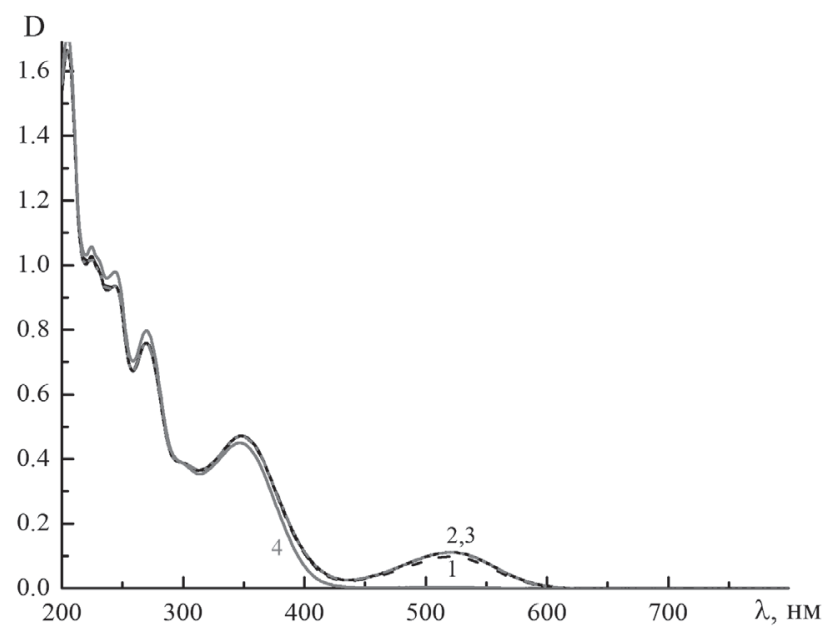

Рис. 8. Спектры поглощения соединения 3

в водно-ацетонитильной смеси до (1), после УФ облучения (2), в процессе темновой релаксации (3) и последующего облучения видимым светом (4) 


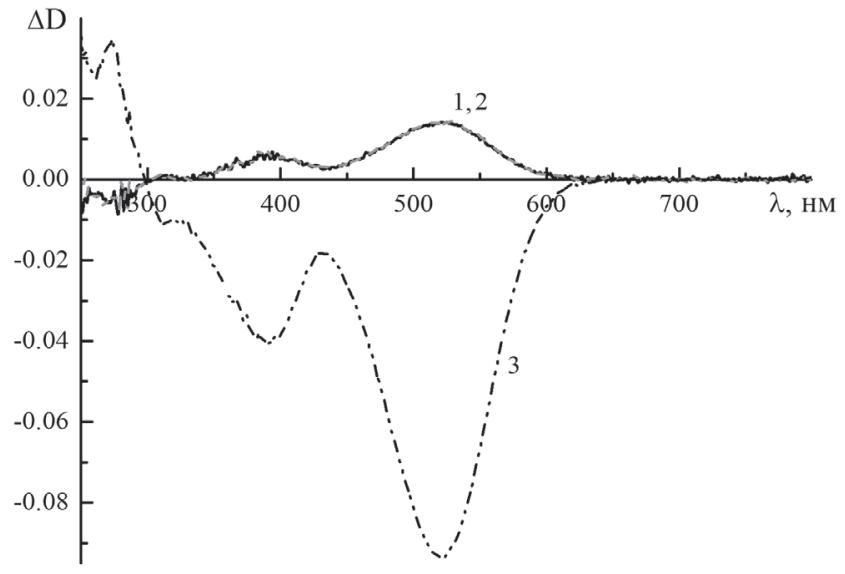

Рис. 9. Разностные спектры поглощения соединения 3 в водно-ацетонитильной смеси после УФ облучения (1), темновой релаксации (2) и облучения видимым светом (3)

Как и в случае спиропирана 2 введение в раствор оксида графена наблюдается резкий гипсохромный сдвиг полосы поглощения (рис. 10, табл. 1), обусловленный образованием предполагаемого протонного комплекса, который также проявляет обратный фотохромизм.

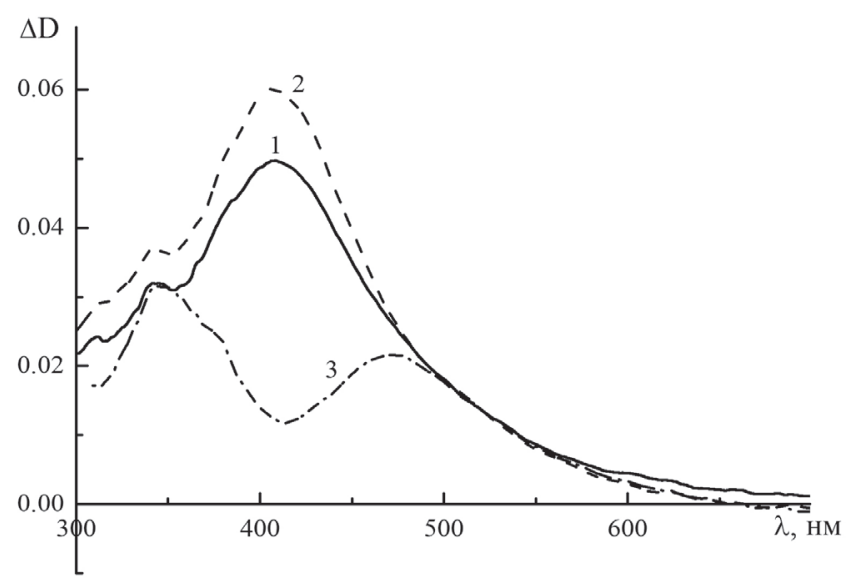

Рис. 10. Разностные спектры поглощения соединения 3 в водно-ацетонитильной смеси в присутствии оксида графена после УФ облучения (1), темновой релаксации (2) и облучения видимым светом (3)

В отличие от спиропирана 3 соединение $\mathbf{4}$ в водно-ацетонитрильной смеси проявляет менее интенсивное окрашивание до облучения (рис. 11, кр. 1). При этом интенсивность полосы поглощения мероцианиновой формы возрастает при УФ облучении (рис. 11, кр. 2), а затем снижается в темноте (рис. 11, кр. 3).

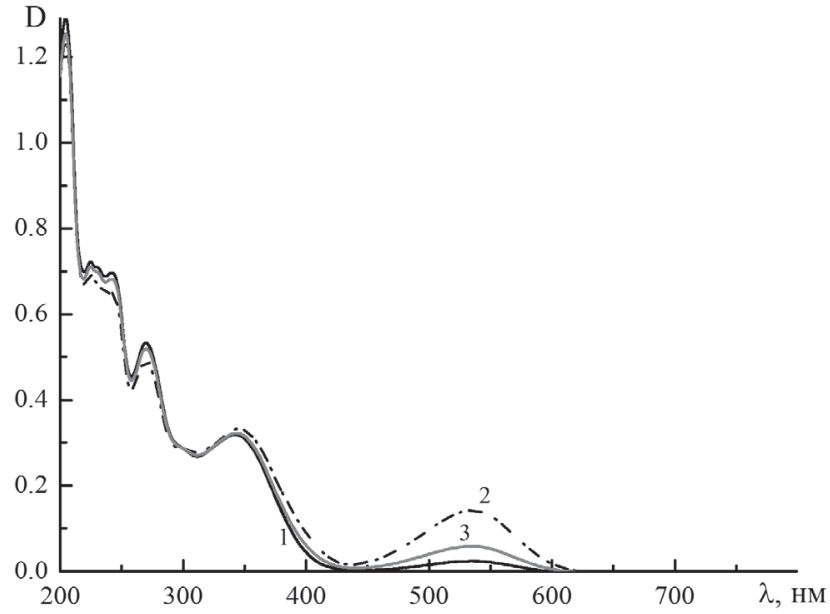

Рис. 11. Спектры поглощения соединения 4 в водно-ацетонитильной смеси до (1), после УФ облучения (2) и в процессе темновой релаксации (3)

Введение в раствор оксида графена, как и в случае предыдущих двух спиропиранов $\mathbf{2}$ и $\mathbf{3}$, приводит к образованию протонированных комплексов, о чем свидетельствует гипсохромный сдвиг максимума полосы поглощения мероцианиновой формы на 123 нм (табл. 1). Образующиеся протонные комплексы проявляют обратный фотохромизм, обратимо обесцвечиваясь под действием видимого света (рис. 12).

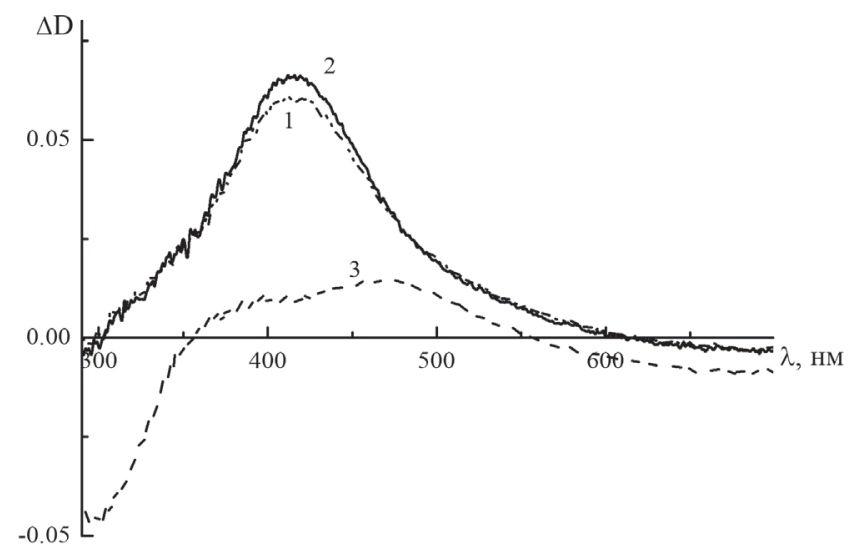

Рис. 12. Разностные спектры поглощения соединения 4 в водно-ацетонитильной смеси в присутствии оксида графена после УФ облучения (1), темновой релаксации (2) и облучения видимым светом (3)

\section{Выводы}

Представленные выше результаты спектральных исследований свидетельствуют о взаимодей- 
ствии молекул спиропиранов с поверхностными гидроксильными группами оксида графена, что проявляется в резком гипсохромном смещении полосы поглощения мероцианиновой формы более, чем на 100 нм, при введении в водно-ацетонитрильный раствор нанопастинок диоксида графена. Это является результатом образования поверхностных протонных комплексов, проявляющих обратный фотохромизм.

В случае хромена также спектрально проявляется взаимодействие молекул фотохромного соединения с поверхностью пластинок оксида графена, но оно менее эффективно по сравнению с молекулами спиропиранов и обусловлено, возможно, физической адсорбцией фотохромных молекул на поверхности нанопластинок оксида графена.

Работа выполнена при поддержке Министерства науки и высшего образования Российской Федераичии в рамках выполнения работ по Государствен- ному заданию ФНИЦ «Кристаллография и фотоника» РАН.

\section{Лumepamypa}

1. Венидиктова О.В., Барачевский В.А., Хузин А.А., Туктаров А.Р., Шиенок А.И., Зайченко Н.Л. Опт. спектр. 2019. T. 127. C. 1025. [Opt. Spectr. 2019. V. 127. P. 1148]. DOI: 10.21883/OS.2019.12.48704.207-19.

2. Photochromic Materials: Preparation, Properties and Applications Eds. H. Tian and J. Zhang. WileyVCH Verlag GmbH \& Co., Weinheim, Germany, 2016.

3. El Maloulibibout M., Noussi L., Lareginie P., Samat A., Guglielmetti R. Mol. Cryst. Liq. Cryst. 1994. V. 246. P. 177. DOI: 10.1080/10587259408037809.

4. Sakata T., Yan Y., Marriott G. J. Org. Chem. 2005. V. 70. P. 2009. DOI: 10.1021/jo048207o.

5. Khuzin A.A., Tuktarov A.R., Barachevsky V.A., Valova T.M., Tulyabaev A.R., Dzhemilev U.M. RSC Advances. 2020. V. 10. P. 15888. DOI: $10.1039 / \mathrm{d} 0 \mathrm{ra} 00217 \mathrm{~h}$.

6. Мурадян В.Е., Езерская М.Г., Смирнова В.И., Кабаева Н.М., Новиков Ю.Н., Парнес З.Н., Вольпин М.Е. ЖОХ. 1991. Т. 61. С. 2626. 